\title{
Estimulação cardíaca com tele-anodo: uma nova técnica para estimulação elétrica do coração
}

Décio S. KORMANN*, José Carlos PACHON MATEOS*, R. Nelson ALBORNOZ*, Paulo de Tarso J. MEDEIROS, Roberto de CAMPOS*, Sívio J. KORMANN**, Júlio César GIZZI*, Luiz Carlos Bento de SOUZA*, Paulo P. PAULISTA*, J. Eduardo M. R. SOUSA*, Adib D. JATENE ${ }^{\star \star *}$

\section{RBCCV}

KORMANN, D. S.; PACHÓN MATEOS, J. C.; ALBORNOZ, R. N.; MEDEIROS. P. T. J.; CAMPOS, R.; KORMANN, S. J.; GIZZI, J. C.; SOUZA L. C. B.; PAULISTA, P. P.; SOUSA, J. E. M. R.; JATENE, A. D. - Estimulação cardiaca com tele-anodo: uma nova técnica para estimulação elétrica do coração. Rev. Bras. Cir. Cardiovasc., 1 (1): 1-13, 1986.

Resumo: Os geradores unipolares, unicâmara, ou dupla-câmara podem ser inibidos, ou deflagrados por ação de miopotenciais esqueléticos. Na experiência dos autores, estas complicaçōes ocorrem em mais de $70 \%$ dos casos. Os geradores bipolares apresentam o risco potencial de provocar arritmias graves, complicação também observada pelos autores. Preocupados com essa situaçāo, os autores idealizaram um tipo de estimulaçāo com o catodo ligado ao coraçāo e o anodo longe do gerador e longe do coraçāo e, por isso, o denominaram "tele-anodo". D. Kormann e J. Pachón tiveram a idéia de posicioná-lo na regiâo esternal. Um dos autores (D. Kormann) idealizou e construiu dois sistemas de tele-anodos esternais e intravasculares. Os esternais podem ser espirais, ou cilíndricos. Na técnica proposta, os autores utilizaram, para estimulação unicâmara, em átrio ou ventrículo, um gerador multiprogramável, bipolar, convencional, com eletrodo unipolar em átrio, ou ventrículo, ligado ao seu polo negativo e o tele-anodo, de preferência esternal, conectado ao polo positivo. Para estimulação dupla-câmara, o mesmo autor idealizou um gerador com três receptáculos. Até março de 1986, foram implantados marcapassos com tele-anodo em 62 pacientes, sendo que 57 receberam tele-anodos esternais ( 51 espirais e 6 cilindricos) e 5 tele-anodos intravasculares. Os geradores utilizados foram de vários fábricantes, sendo $35 \mathrm{VII}, \mathrm{M}, 23 \mathrm{DDD}, \mathrm{M}, 3 \mathrm{AAI}, \mathrm{M}$ e 1 VVI, $\mathrm{OB}$. Em todos os casos, as medidas per e pós-operatórias foram muito semelhantes às convencionais. Não houve nenhuma complicação diretamente relacionada com a técnica proposta. Sessenta e um pacientęs com tele-anodo, examinados na clínica de marcapasso, apresentaram condiçōes normais. Concluem os autores que a estimulação cardiaca com tele-anodo diminui, significativamente, as complicaçōes existentes em sistemas unipolares e bipolares.

DESCRITORES: tele-anodo; estimulaçāo cardiaca, técnicas: marcapassos cardiacos

\section{INTRODUÇĀO}

A inibição de marcapassos de demanda unipolares por miopotenciais originados de músculos esqueléticos foi primeiramente relatada por PARKER et alii ${ }^{20}$, em 1969, e, mais tarde, por WIRTZFELD et alii $^{25}$ e outros autores ${ }^{13}{ }^{18}$. Estas inibições se devem ao fato de que os filtros dos geradores unipolares não conseguem diferenciar os miopotenciais esqueléticos dos miopotenciais gerados pelo

Trabalho realizado no Instituto Dante Pazzanese de Cardiologia, São Paulo, SP, Brasil.

Apresentado ao 13: Congresso Nacional de Cirurgia Cardiaca, São Paulo, SP, 4 e 5 de abril, 1986.

Laureado com o "Prêmio de Cirurgia Cardíaca - 1986".

- Do Instituto Dante Pazzanese de Cardiologia.

.. Da Clinica Kormann, Curitiba, PR.

*.. Do Instituto do Coração do Hospital das Clinicas da Faculdade de Madicina da Universidade de São Paulo.

Endereço para separatas: D. S. Kormann. Caixa Postal 215. São Paulo, SP, Brasil. 
coração. BREIVIK \& $\mathrm{OHM}^{3}$ e HAUSER ${ }^{8}$ relacionaram sintomas em pacientes portadores e geradores unipolares com inibiçōes por miopotenciais, através da eletrocardiografia dinâmica. Quando os miopotenciais se assemelham a uma interferência contínua, os geradores podem reverter para freqüências assincrônicas, podendo provocar arritmias (BRAGA et alii ${ }^{2}$ ).

Os autores têm estudado esses problemas, desde 1978 , através de metodologia própria ${ }^{7}, 11$. 12. 14. 23 . Devido aos resultados encontrados, passaram a usar, a partir de 1980 , estimulação bipolar sempre que possivel. Entretanto, em 1984, observaram que a estimulação bipolar foi responsável pelo aparecimento de arritmias graves, em três pacientes chagásicos, um dos quais veio a falecer. Nos outros dois casos, foi possivel comprovar a gênese da arritmia, que era ligada à estimulação anódica. Revendo a literatura, encontraram vários trabalhos mostrando os riscos da estimulação bipolar, como os de PRESTON ${ }^{22}$, FURMAN \& MEHRA ${ }^{5}$, MERX et alii ${ }^{15}$ e FURMAN et alii ${ }^{4}$.

Portanto, ambos os sistemas de estimulação cardiaca existentes, unipolares e bipolares, apresentam a possibilidade de complicações sérias. Esta situação se complica ainda mais com os marcapassos de dupla-câmara, que apresentam um circuito bastante sensivel, ligado ao átrio. Podem ocorrer inibiçōes, reversōes e deflagraçōes do circuito ventricular em freqüências altas por miopotenciais esqueléticos ${ }^{10},{ }^{17}$. Preocupados com esta situação dos sistemas unipolares e bipolares, os autores idealizaram um tipo de estimulação com o catodo no coração e com o anodo longe do gerador e longe do coração e por isso o denominaram de "tele-anodo".

\section{MATERIAL E MÉTODO}

Para a estimulação cardiaca com tele-anodo, um dos autores (D. Kormann) idealizou e construiu dois tipos de tele-anodo: o esternal e o intravascular*.

Tele-anodo esternal: pode ser de dois tipos: espiral ou cilindrico (Figura 1). O tele-anodo esternal consta de eletrodo em mola, revestido por tubo de silicone, o qual termina em um disco do mesmo material, com $2 \mathrm{~cm}$ de diâmetro e $1 \mathrm{~mm}$ de espessura, sobre o qual fixa-se a mola enrolada em forma de espiral. Este eletrodo é implantado no subcutâneo da região esternal baixa, próximo ao apêndice xifóide. Para tanto, faz-se uma pequena incisão ao nivel da quarta cartilagem costal e confec- ciona-se uma pequena loja, exatamente sobre o esterno, onde o tele-anodo espiral é posicionado, com a espiral voltada para a pele. A espiral do tele-anodo deve ficar previamente submersa em uma cuba com soró fisiológico. A loja deve ser suficientemente ampla para que o tele-anodo espiral não fique sob tensões e deve ficar situada na linha mediana, sobre a extremidade inferior do corpo do esterno. Em seguida, com um tunelizador, a extremidade do tele-anodo que deverá ser conectada ao gerador é passada para a loja do marcapasso. A pequena loja deve ser suturada, tomando-se o cuidado de que todo $o$ ar de seu interior seja eliminado. Durante as medidas de limiar, uma pequena pressão sobre a pele, onde estiver a espiral, é interessante para melhorar o contato com o subcutâneo.

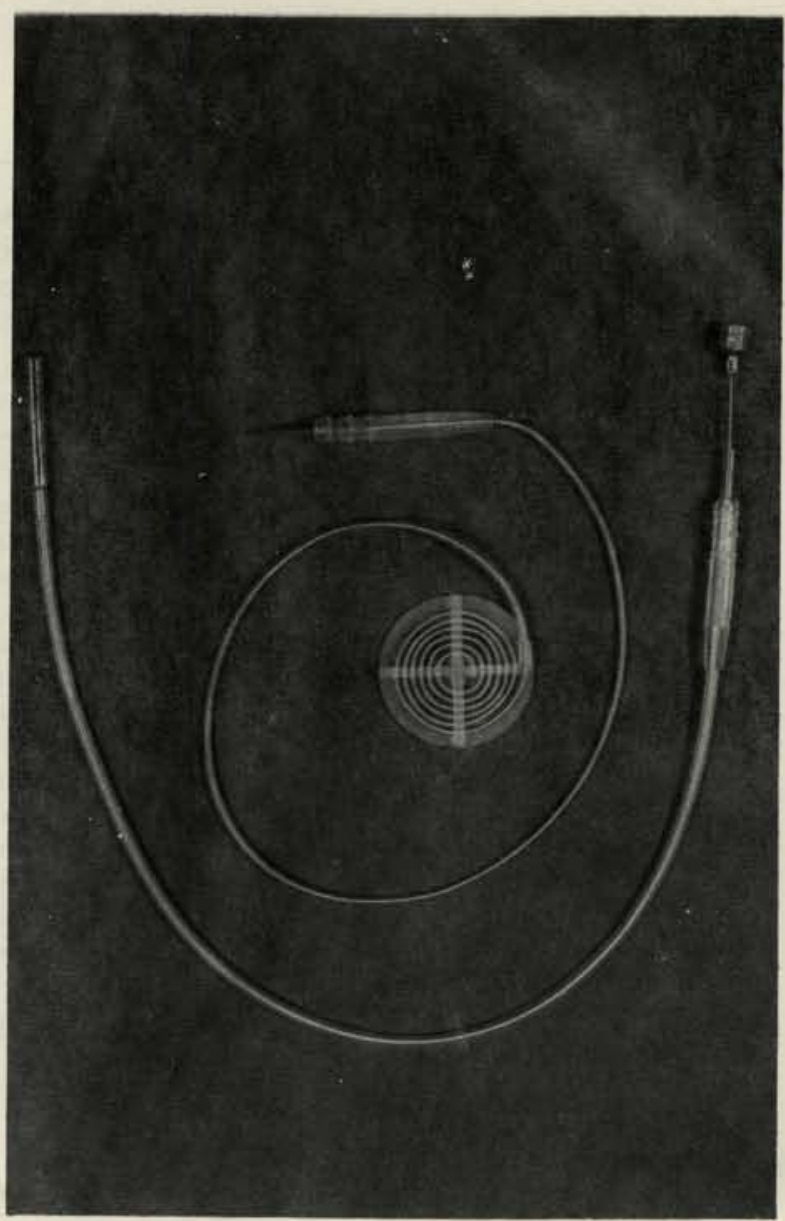

Fig. 1 - Tele-anodos esternais espiral e cilindrico

O tele-anodo cilíndrico é constituído, também, por uma mola condutora revestida de silicone e que termina em uma estrutura metálica, medindo $25 \mathrm{~mm}$ de comprimento por $3 \mathrm{~mm}$ de diâmetro.

Fabricados atuaimente pela Biotronik Ind. e Com. de Produtos Médicos e Hospitalares Ltda 
Para o posicionamento deste tele-anodo esternal, os autores desenvolveram um sistema introdutor e o mesmo pode ser posicionado na região esternal baixa, partindo da própria loja, sem necessidade de nova incisão. O tele-anodo esternal espiral foi utilizado em 51 pacientes e o tele-anodo esternal cilíndrico, em 6 casos.

Tele-anodo intravascular : consta da mola condutora revestida por tubo de silicone e que termina em uma estrutura cilíndrica, medindo $15 \mathrm{~mm}$ de comprimento com $1,2 \mathrm{~mm}$ de diâmetro. Este eletrodo é utilizado somente em condiçōes em que não é possivel usar-se o anterior, ou os anteriores, e pode ser posicionado na cava superior, na cava inferior, ou na artéria pulmonar. Foi utilizado em apenas 5 pacientes.
Para estimulação de dupla-câmara, o mesmo autor (D. Kormann) idealizou um gerador que possui três receptáculos: um para conexão com eletrodo ventricular, outro para conexẫo com o eletrodo atrial e outro para conexão com o tele-anodo. A estrutura metálica do gerador é isolada, não sendo, portanto, eletricamente ativa (Figura 2$)^{*}$.

\section{CASUISTICA}

Foram implantados marcapassos de vários fabricantes com o tele-anodo, no período de agosto de 1984 a março de 1986, em 62 pacientes. Três casos receberam geradores AAI, M com tele-anodo esternal espiral; 27 casos receberam geradores VVI, M também com tele-anodo esternal espiral; 21 casos receberam geradores DDD, $M$ com
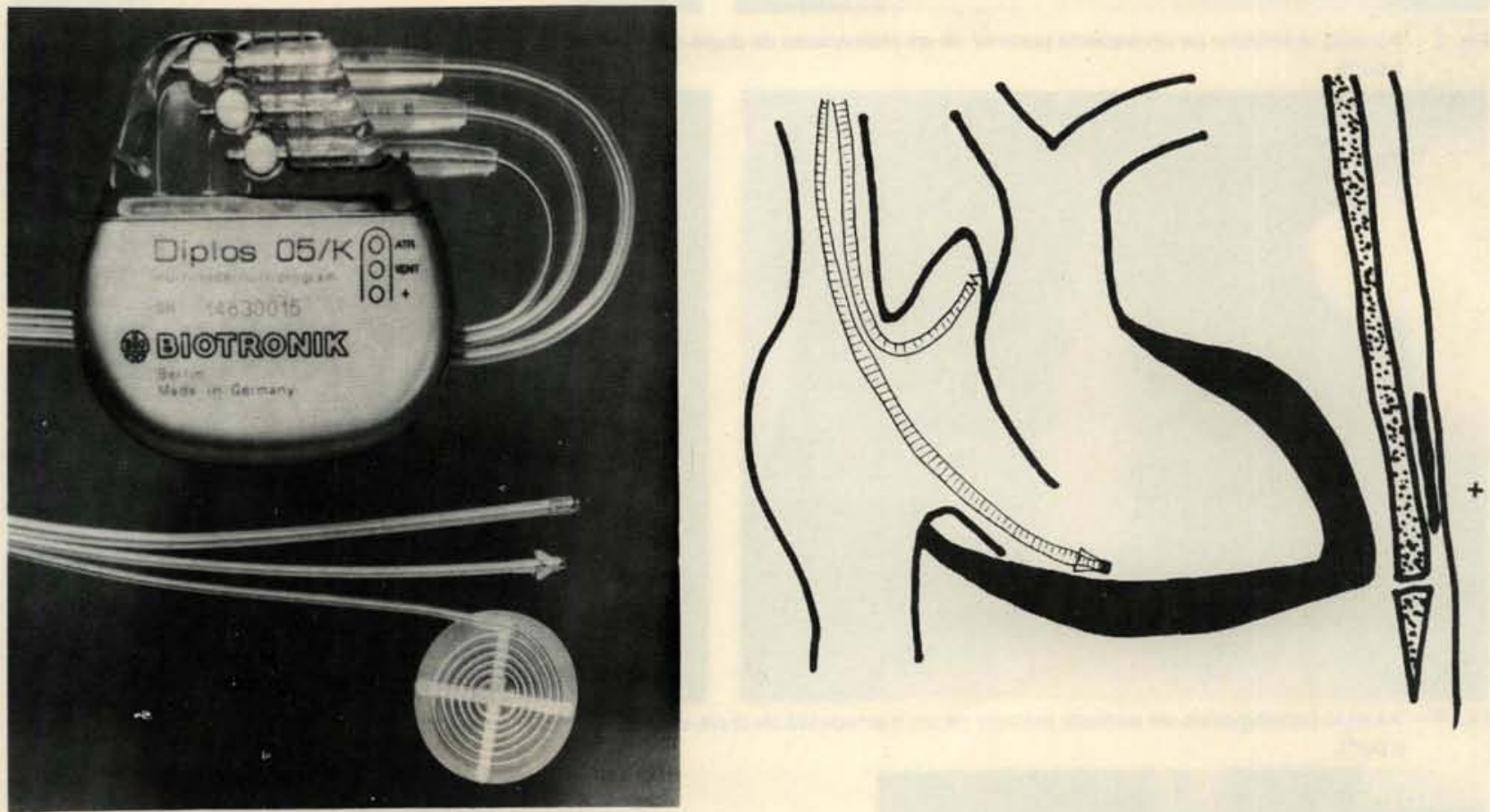

Fig. 2-Marcapasso de dupla-câmara (Biotronik-Diplos 05-K) com très receptáculos, um para o eletrodo atrial, um para o eletrodo ventricular e um para o tele-anodo e a esquematizaçăo do posicionamento dos eletrodos

Para estimulação unicâmara em átrio ou ventrículo, os autores utilizaram geradores bipolares, multiprogramáveis de vários fabricantes. Como catodo, utilizaram um eletrodo unipolar ligado ao polo negativo do gerador, sendo o tele-anodo conectado ao polo positivo do mesmo. Um gerador unicâmara dotado de função antitaquicardia foi bipolarizado pela técnica dos autores ${ }^{17}$. três receptáculos (Figura 3); 6 casos receberam tele-anodo esternal cilíndrico, sendo que, em 1 paciente, utilizou-se o gerador DDD, M (Figura 4) e, em 5 outros casos, geradores VVI, M; 5 pacientes receberam tele-anodo intravascular, usando-se gerador DDD, M em 1 paciente, VVI, M em 3 e VVI, $\mathrm{OB}$ (gerador com funçâo antitaqui) em 1 caso (Figu: ra 5). 

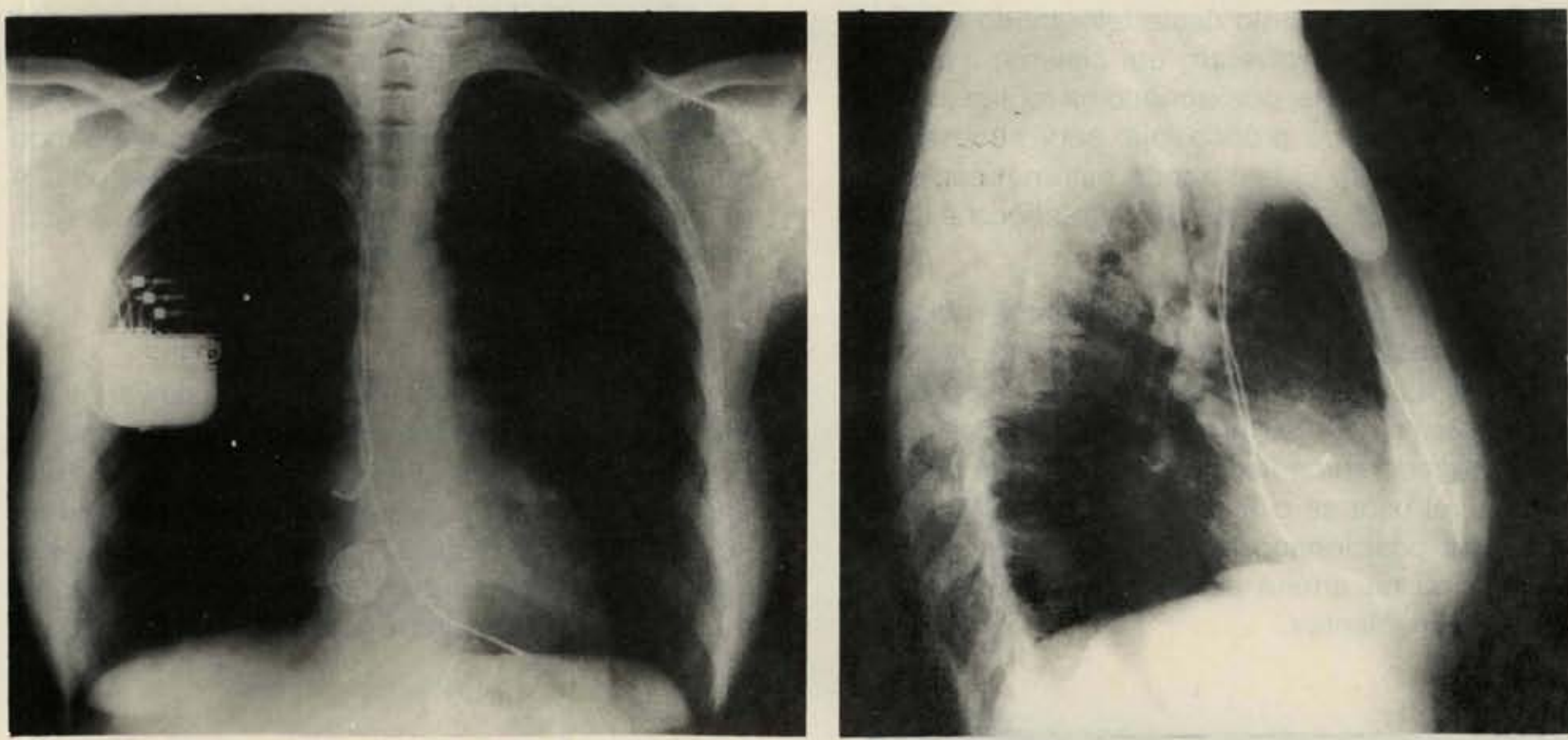

Fig. 3 - Aspecto radiológico de um paciente portador de um marcapasso de dupla-câmara, com tele-anodo esternal espiral, em posição póstero-anterior e perfil.
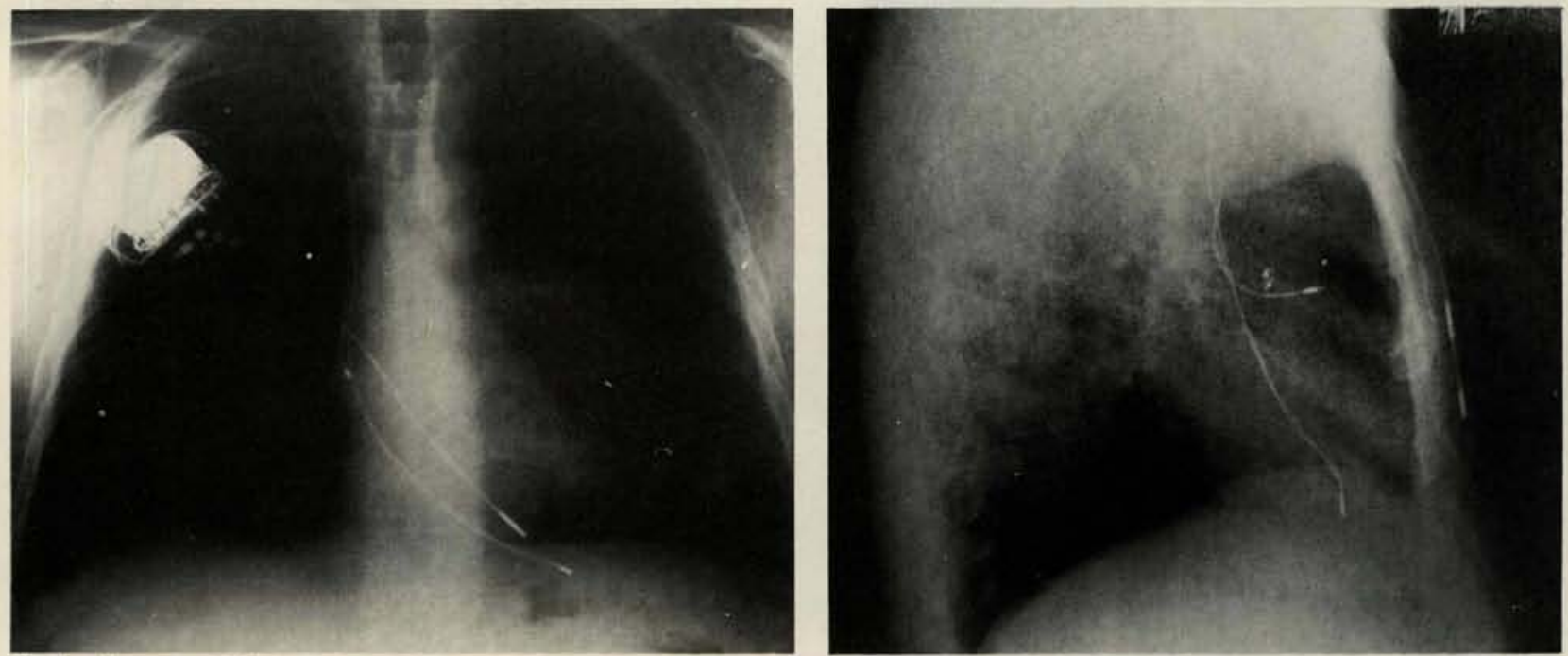

Fig. 4 - Aspecto radiológico de um paciente portador de um marcapasso de dupla-câmara com tele-anodo esternal cilíndrico em posição póstero-anterior e perfil.
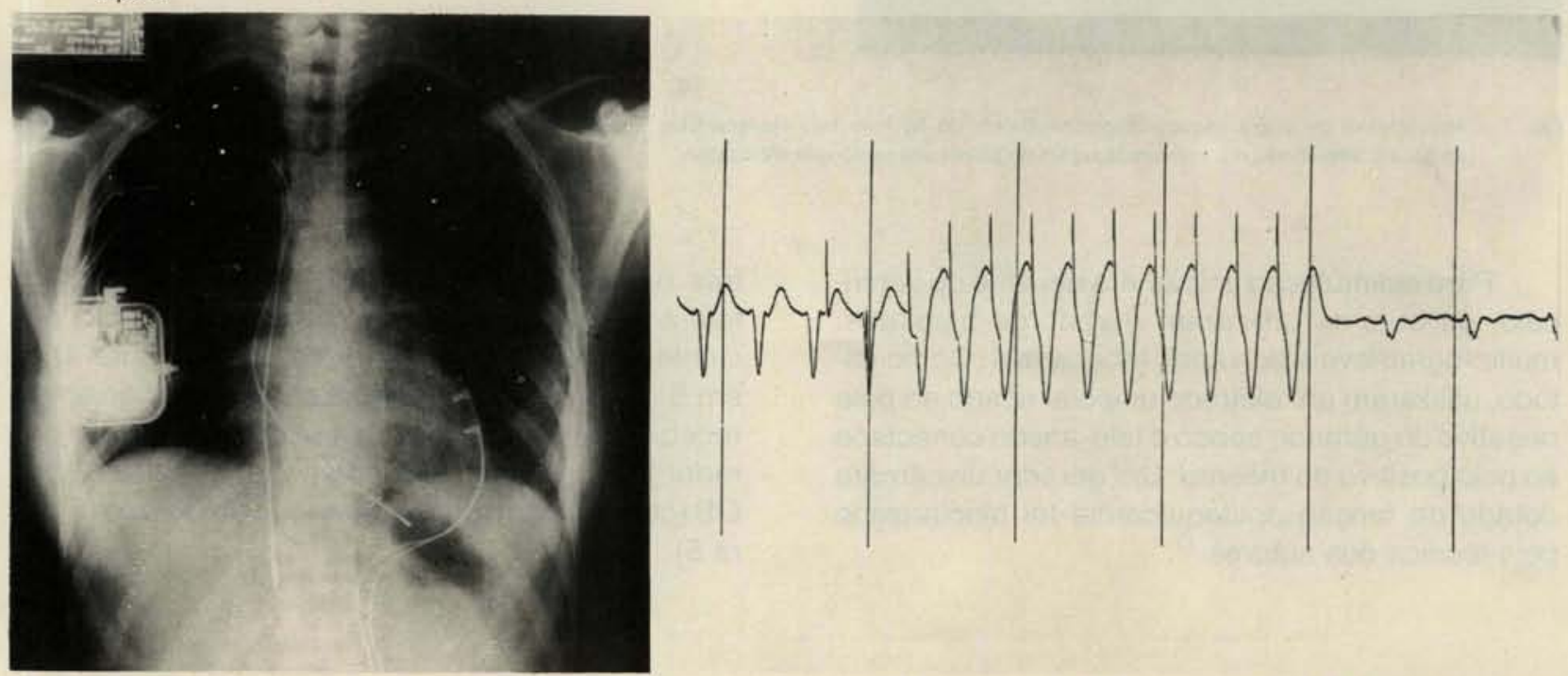

Fig. 5 - Aspecto radiológico de uma paciente apresentando um gerador com função anti-taquicardia "Bipolarizado" e ECG da paciente tendo sua taquicardia eliminada pelo gerador nesta situação. 
Durante os implantes, foram feitos estudos comparativos entre as medidas unipolares convencionais (entre loja e catodo) e as medidas entre o tele-anodo e o catodo. Foram analisadas as curvas intensidade-duração ventriculares e impedâncias ventriculares (Figura 6 ), as curvas intensidadeduração atriais e impedâncias atriais (Figura 7), os QRS e ondas P (Figura 8). Pode ser observado que os parâmetros medidos com tele-anodo são muito semelhantes aos parâmetros unipolares convencionais, havendo apenas um pequeno aumento dos limiares, devido a uma impedância ligeiramente maior, nas medidas com tele-anodo. As ondas $P$ obtidas com o tele-anodo foram, também, ligeiramente maiores em voltagem.

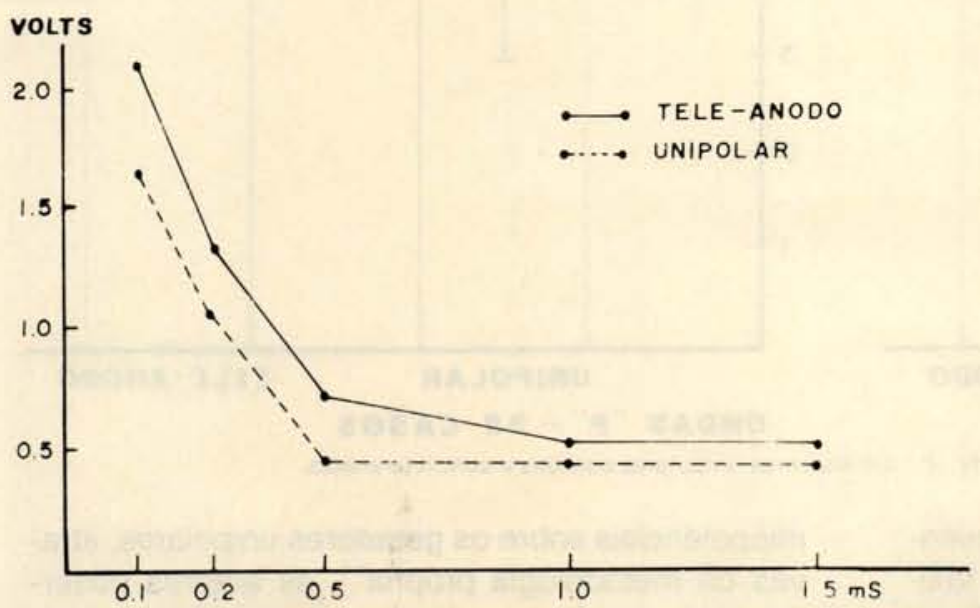

CURVAS INTENSIDADE-DURACAOOO VENTRICULARES AGUDAS - 57 CASOS

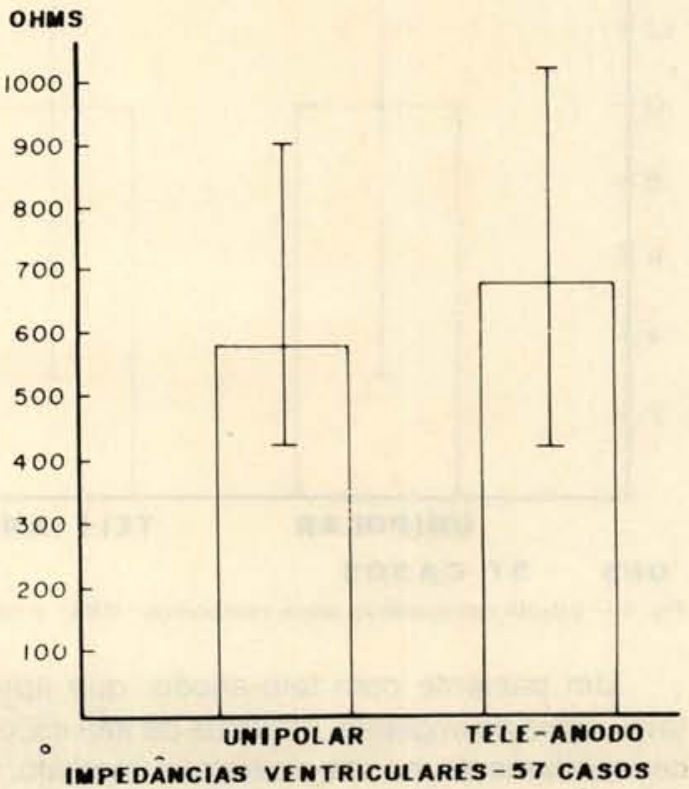

Fig. 6 - Estudo comparativo entre curvas intensidade-duração ventriculares agudas e impedâncias em sistemas unipolares comuns e com tele-anodo.
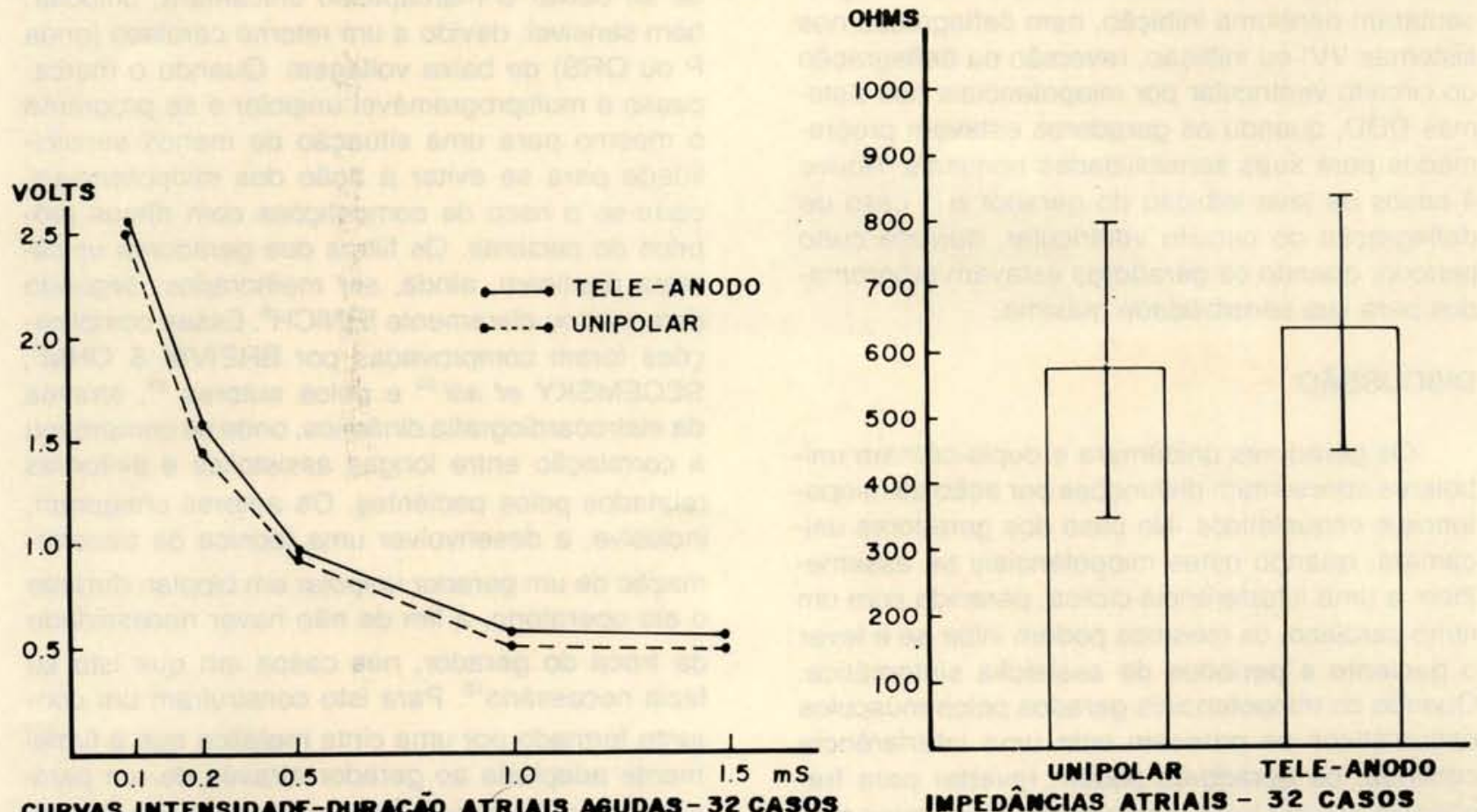

Fig. 7 - Estudo comparativo entre curvas intensidade-duraçăo atriais agudas e impedâncias em sistemas unipolares comuns e com tele-anodo 

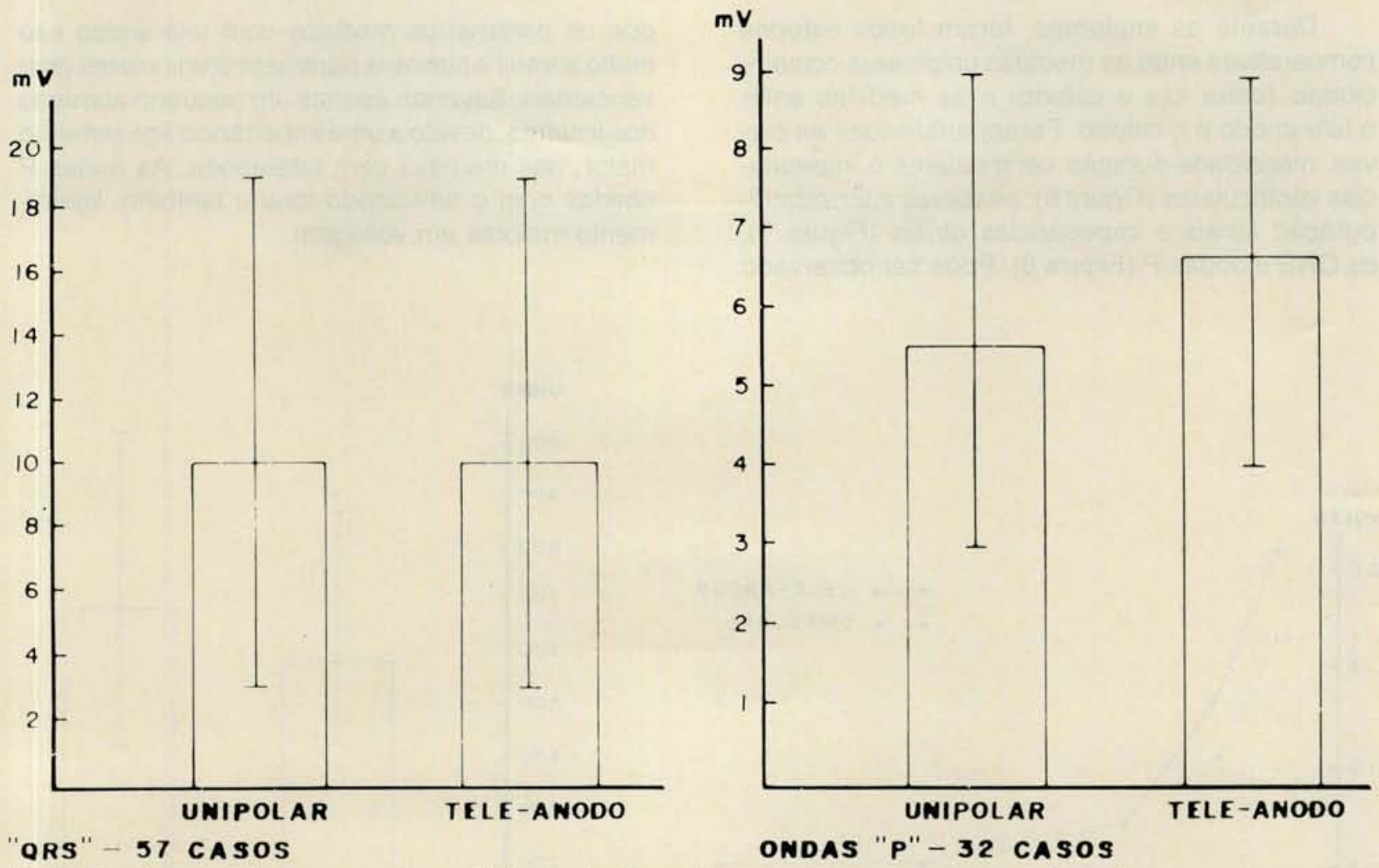

Fig. 8 - Estudo comparativo entre complexos QRS e onda $P$ em sistemas unipolares comuns e com tele-anodo.

Um paciente com tele-anodo, que apresentava, antes do implante, arritmias de alto risco, faleceu subitamente, no pós-operatório imediato. Outro paciente, portador de um sistema DDD, apresentou aumento de limiar no eletrodo ventricular, sendo o mesmo reposicionado. Os 61 pacientes restantes, avaliados na clinica de marcapasso, não apresentaram nenhuma inibição, nem deflagração nos sistemas VVI ou inibição, reversão ou deflagração do circuito ventricular por miopotenciais nos sistemas $\mathrm{DDD}$, quando os geradores estavam programados para suas sensibilidades nominais. Houve 4 casos de leve inibição do gerador e 1 caso de deflagração do circuito ventricular, durante curto periodo, quando os geradores estavam programados para sua sensibilidade máxima.

\section{DISCUSSĀO}

Os geradores unicâmara e dupla-câmara unipolares apresentam disfunções por ação de miopotenciais esqueléticos. No caso dos geradores unicâmara, quando estes miopotenciais se assemeIham a uma interferência cíclica, parecida com um ritmo cardíaco, os mesmos podem inibir-se e levar o paciente a períodos de assistolia sintomática. Quando os miopotenciais gerados pelos músculos esqueléticos se parecem com uma interferência contínua, os geradores podem reverter para freqüência assincrônica, competindo com rítmos próprios do paciente ${ }^{12}{ }^{20}$. Pesquisando a ação dos miopotenciais sobre os geradores unipolares, através de metodologia própria ${ }^{11}$, os autores observaram que este fato ocorria em $70 \%$ dos geradores implantados, coincidindo com outros trabalhos existentes na literatura ${ }^{1}, 19,21,24$. Esta situação complica-se ainda mais quando há necessidade de se deixar o marcapasso unicâmara, unipolar, bem sensivel, devido a um retorno cardíaco (onda P ou QRS) de baixa voltagem. Quando o marcapasso é multiprogramável unipolar e se programa o mesmo para uma situação de menos sensibilidade para se evitar a ação dos miopotenciais, corre-se o risco de competições com rítmos próprios do paciente. Os filtros dos geradores unicâmara precisam, ainda, ser melhorados, segundo demonstrou claramente IRNICH${ }^{9}$. Essas complicações foram comprovadas por BREIVIK \& $\mathrm{OHM}^{3}$, SECEMSKY et alii ${ }^{24}$ e pelos autores ${ }^{23}$, através da eletrocardiografia dinâmica, onde se comprovou a correlação entre longas assistolias e sintomas relatados pelos pacientes. Os autores chegaram, inclusive, a desenvolver uma técnica de transformação de um gerador unipolar em bipolar, durante 0 ato operatório, a fim de não haver necessidade da troca do gerador, nos casos em que isto se fazia necessário ${ }^{12}$. Para isto construíram um conjunto formado por uma cinta metálica que é firmemente adaptada ao gerador através de um parafuso, tendo soldado a ela um borne, para conexão com o terminal positivo do eletrodo e uma capa 
de silicone que envolve e isola totalmente o gerador. Esta capa é vedada com adesivo médico.

Devido às suas observações e aos dados de literatura, a partir de 1980 , os autores passaram a utilizar geradores bipolares. Observaram, então, outro tipo de complicação. Um paciente chagásico com distúrbio do sistema éxcito-condutor do coração, após o implante de um marcapasso bipolar, começou a apresentar arritmias rebeldes a toda a terapêutica convencional, tendo recebido vários choques de cardioversão, evoluindo para óbito: Outro paciente, apresentando a mesma complicação, foi levado para a sala de cirurgia. Através de determinações com extra-estímulo, utilizando-se, para as medidas, o estimulador de Pachón, verificou-se que existia uma diferença de $40 \mathrm{mseg}$ entre o período refratário efetivo do ventrículo com estimulação catódica e estimulação anódica. Entre o catodo e o anodo, havia uma micro-reentrada responsável pelas taquicardias do paciente (Figura 9). Neste caso, foi retirado o eletrodo bipolar do ventrículo, colocando-se o mesmo na veia cava inferior. Colocou-se um outro eletrodo unipolar em ventrículo, ligado ao polo negativo do mesmo gerador bipolar, conectando-se o anel do eletrodo de cava inferior ao seu polo positivo. O paciente melhorou significativamente e obteve alta hospitalar.

Outra paciente, também chagásica, começou a apresentar arritmias ventriculares, extremamente freqüentes, após o implante de um marcapasso bipolar. A mesma foi levada a um estudo eletrofisiológico e foi provocada a sua taquicardia. Através de um eletrodo colocado junto ao anodo de seu eletrodo bipolar, foi possível observar-se que era neste ponto o local da despolarização mais precoce durante a taquicardia (Figura 10, VDI). Esta paciente recebeu um tele-anodo esternal, com uma evolução muito boa, desaparecendo as arritmias.

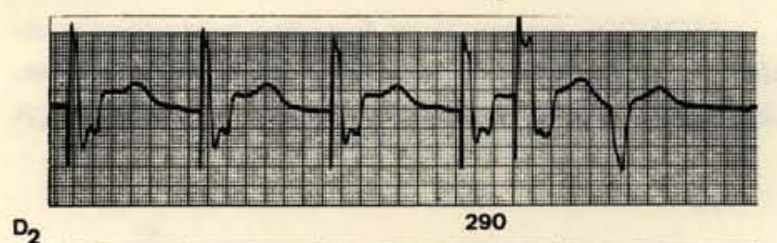

$D_{2}$
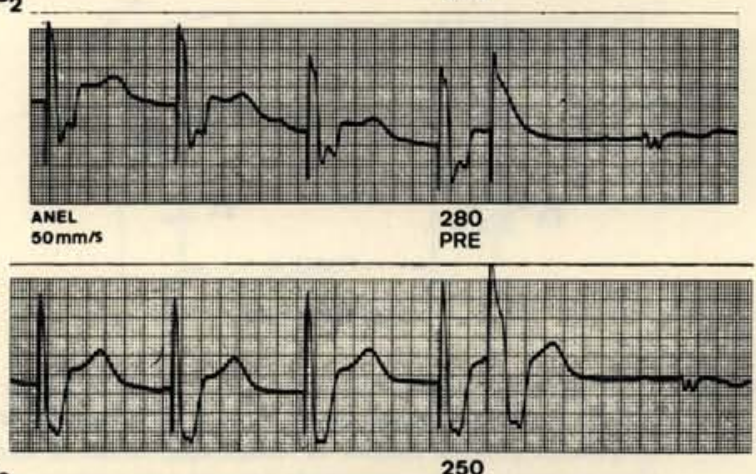

$\partial_{2}$

250

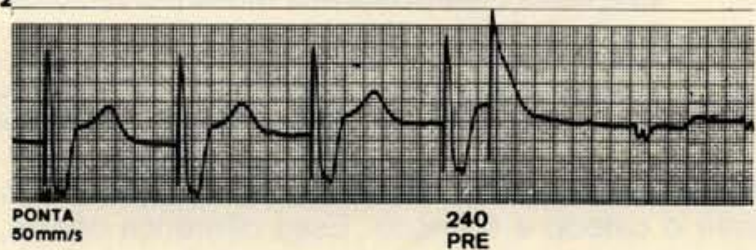

Fig. 9 - Determinação dos periodos refratários efetivos de ventriculo com estimulação anódica no anel de eletrodo bipolar crônico e na ponta do mesmo, com estimulação catódica, em pacientes com taquicardias induzidas pelo marcapasso
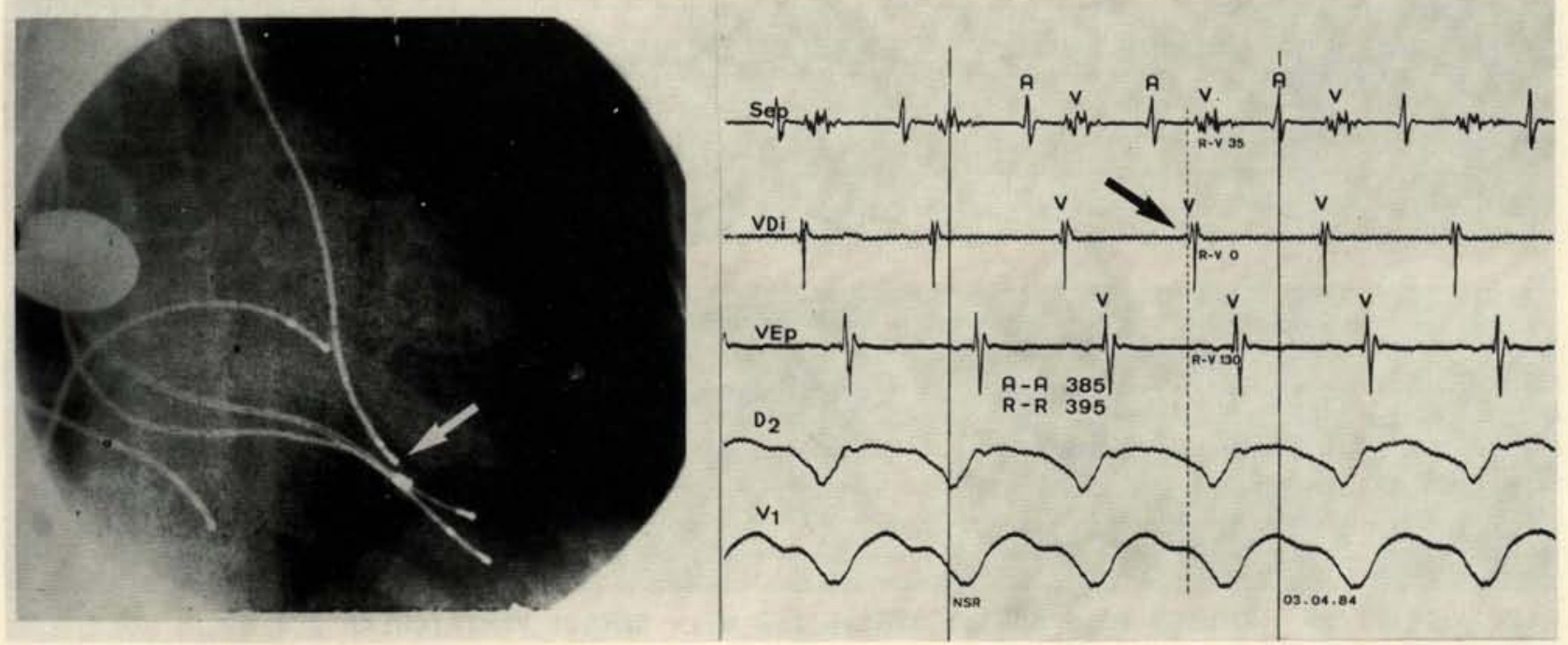

Fig. 10 - Paciente portadora de marcapasso bipolar e taquicardias ventriculares freqüentes apos o implante. Durante estudo eletrofisiológico foi provocada a taquicardia e com eletrodo colocado junto ao anodo (anel) obtem-se a despolarização ventricular mais precoce (origem da taquicardia). 
Baseados nestes casos os autores fizeram uma revisão da bibliografia existente e encontraram vários trabalhos como os de PRESTON ${ }^{22}$. FURMAN \& MEHRA ${ }^{5}$, MERX et alii ${ }^{15}$ e FURMAN et alii ${ }^{4}$, onde, claramente, se mostra a possibilidade do sistema bipolar provocar arritmias.

MOND ${ }^{16}$, em seu livro, faz uma cuidadosa revisão da arritmogenicidade dos sistemas bipolares. Uma das causas principais é a possivel diferença

A

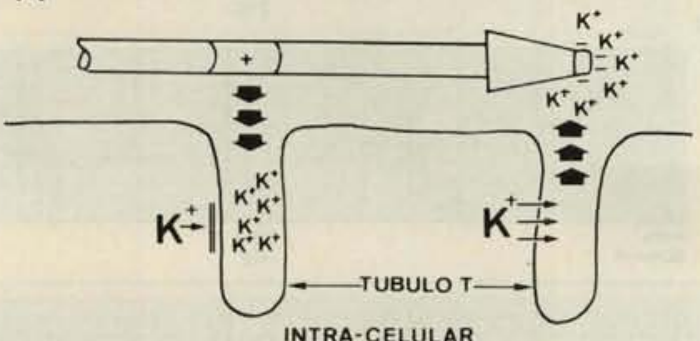

pode ser um dos mecanismos que produzem as arritmias (Figura 11).

Os marcapassos de dupla-câmara, unipolares, além dos problemas de inibição e reversão para freqüências assincrônicas por miopotenciais, apresentam, ainda, a possibilidade de deflagração do circuito ventricular, em freqüências altas, por miopotenciais sentidos pelo circuito atrial. $\mathrm{Na}$ experiência dos autores, as inibiçōes ocorrem em $86,9 \%$
B

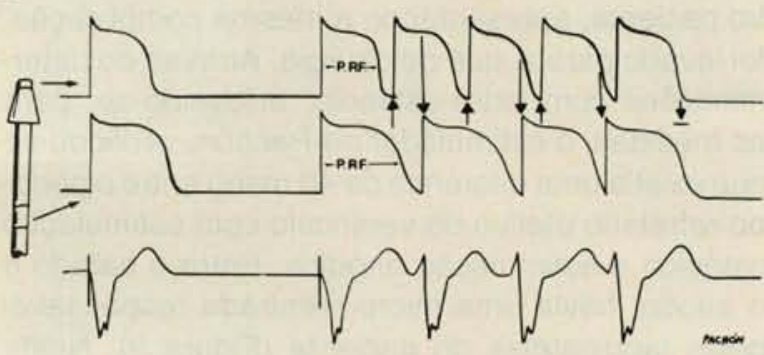

Fig. 11 - Em A vemos esquematizada a relação do eletrodo bipolar e os Túbulos $T$ das células miocárdicas. A drenagem do potássio intracelular. nas fases 2 e 3 do potencial de ação, é eletricamente dificultada pelo anodo $(+)$ e facilitada pelo catodo (-). A dificuldade na saida do potássio provoca demora na recuperaçâo celular às custas de aumento dos períodos refratários e do periodo supernormal. Este último efeito explica a hiperexcitabilidade induzida pela estimulaçāo anódica. Em B vemos representados potenciais de ação de células miocárdicas ao nivel do anodo e catodo de eletrodos bipolares. A dificuldade na saida do potássio na regiảo anódica explica um potencial de açâo mais longo, ocorrendo exatamente o oposto na regiáo do catodo, que apresenta potencial de ação mais curto. Estando as duas regiōes celulares em continuidade anatômica, pode se desenvolver a microreentrada, pois uma das áreas se recupera antes sendo reexcitada pela outra de recuperaçăo mais lenta (dispersảo da retratariedade).

entre os períodos refratários efetivos de ventrículo, entre o catodo e o anodo. Essa diferença ocorre, provavelmente, devido a diferença de íons próximo ao anodo e ao catodo. Ao nível dos túbulos $T$ da membrana, a liberação do ion potássio, no final do potencial de ação, ocorre com mais facilidade, próximo ao catodo do que próximo ao anodo. Este dos casos e as deflagraçōes ou reversōes em $78,2 \%$ dos casos (Figura 12). MORACCHINI et alii 17. KLEINERT et alii ${ }^{10}$ e GABRY et alii ${ }^{6}$ também apresentam números semelhantes para os sistemas de dupla-câmara unipolares, independentemente de seus fabricantes.
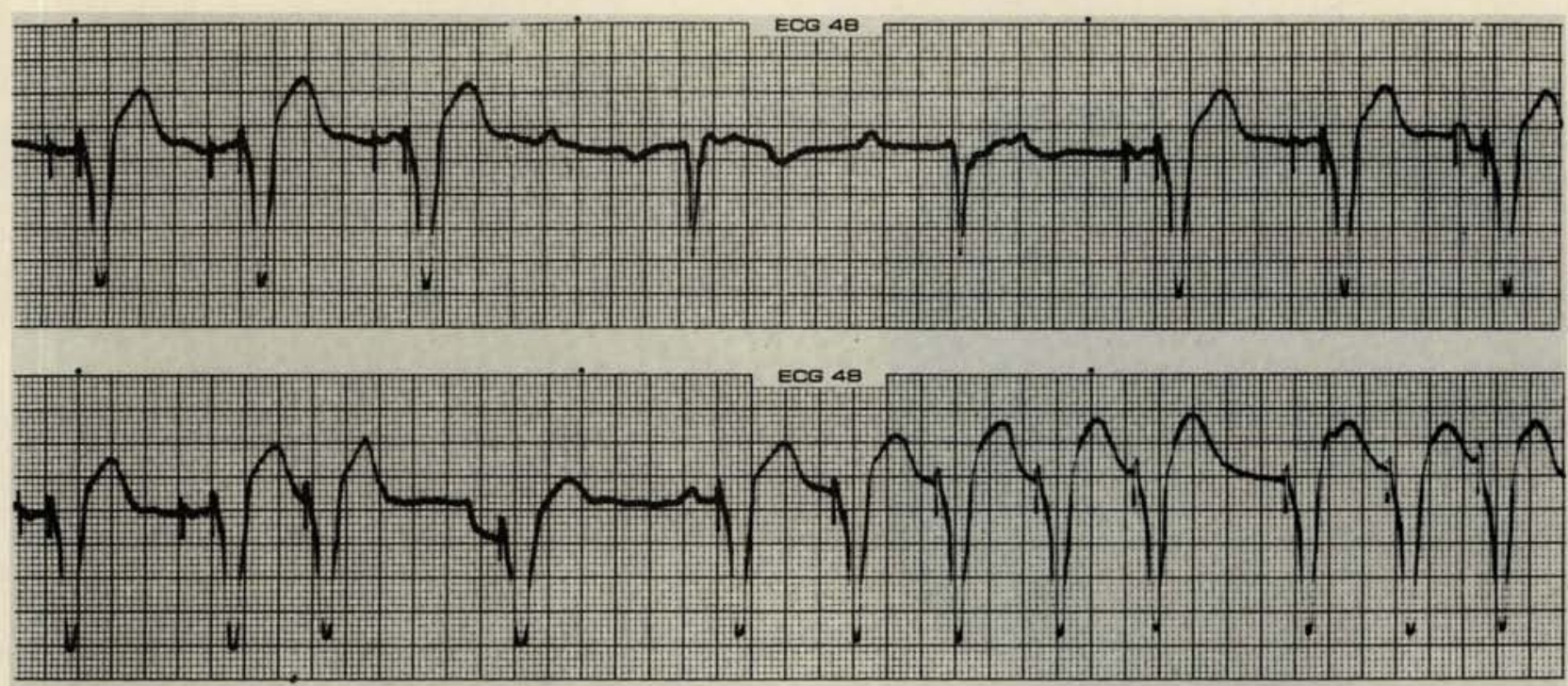

A.F. = 14/03/86 - DIPLOS 05 - SENS.: ATRIAL 1,2 mV - SENS.: VENTRICULAR $2,4 \mathrm{mV}$

FREQ.: $62 \mathrm{ppm}$ - CONTR. ISOMETRICA DE $10 \mathrm{KGF}$ - DERIVAÇAO: TESTA- PERNA ESQUERDA.

Fig. 12 - Paciente portador de gerador de dupla-câmara unipolar programado para sensibilidades nominais em átrio e ventriculo, sendo submetido a contração isométrica de $7 \mathrm{Kgf}$ - derivaçāo testa-perna esquerda - Observaram-se inibiçōes do circuito ventricular e deflagraçōes ventriculares em frequeèncias altas, provocadas por miopotenciais esqueléticos, sentidos. 
Através da estimulação elétrica com o tele-anodo, técnica atualmente proposta pelos autores, todas essas complicações se reduzem significativamente. Os autores dão preferência ao tele-anodo
No ECG, chama-se atenção para que os estimulos do gerador são de pequena amplitude, sendo maiores em $V_{1}$ e $V_{2}$. Com contração isométrica potente e com levantamento de pesos, freqüente-
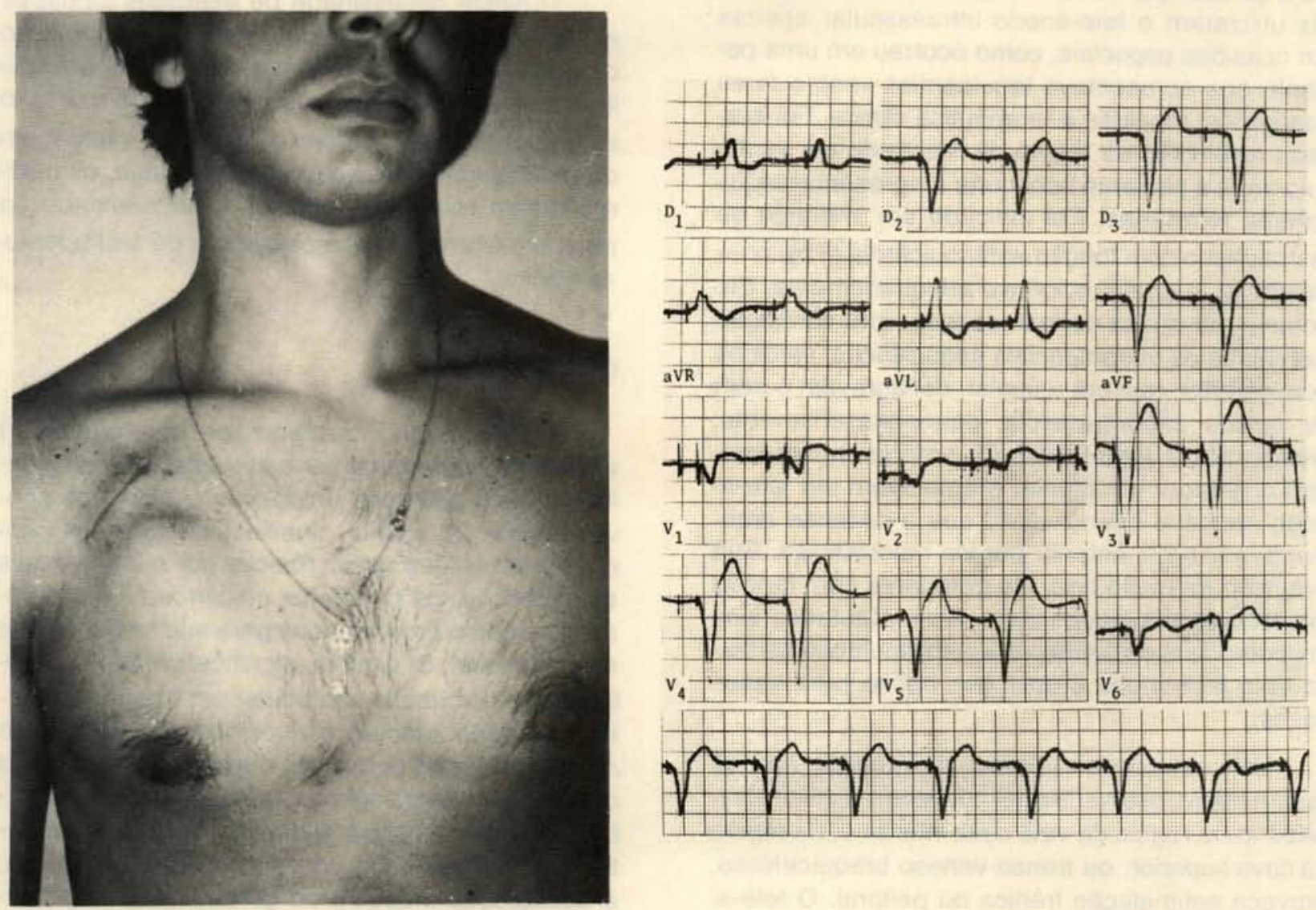

Fig. 13-Paciente portador de um gerador de dupla-cảmara com tele-anodo esternal espiral e seu EC G, onde se observa a pequena amplitude dos estimulos do gerador, sendo maiores em $V_{1}$ e $V_{2}$. próximo ao tele-anodo.

esternal espiral ou cilíndrico. Na Figura 13, pode ser observado $o$ aspecto estético de um gerador de dupla-câmara com tele-anodo implantado e o eletrocardiograma do paciente. mente não se observa nenhuma alteração do ritmo do paciente, mesmo com o gerador programado para sua sensibilidade máxima (Figura 14).

INTERROGATED DATA

MODE DDD UNCOMM.

RATE 62 PPA

P.AMPL.A. 5.0 PN

\begin{tabular}{lll} 
SENS. A & 0.6 & $\mathrm{mV}$ \\
\hline REFRACT.A. & 400 & $\mathrm{mI}$
\end{tabular}

UTR RESP. $2: 1$

UTR

AY-DELAY 175 NOF

AV-FALLB.

P.AMPL.V. 5.0 V

F. WIDTH V. $0.5 \mathrm{~ms}$

\begin{tabular}{lll} 
SENS. V & 1.6 & $\mathrm{mV}$ \\
\hline REFRACT.V. & $390 \mathrm{nE}$
\end{tabular}

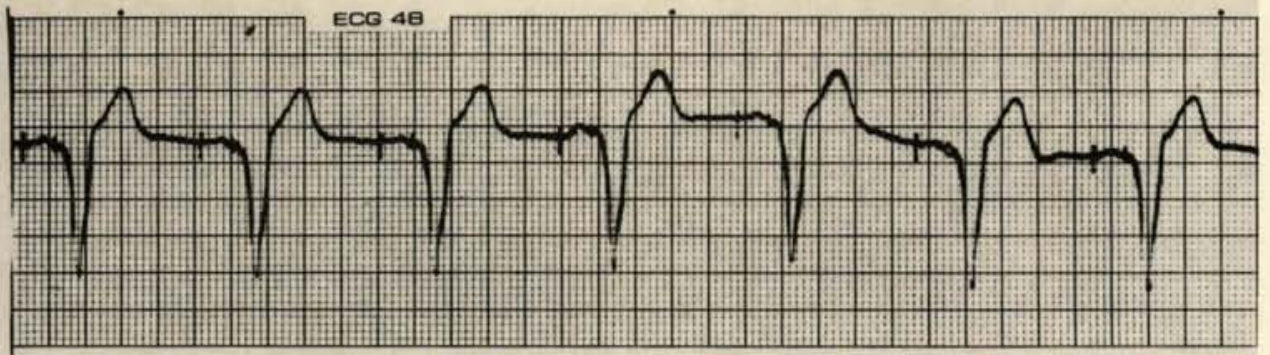

HYSTERESIS OFF

A.P. - 14/03/86 - DIPLOS $05 \mathrm{~K}$ - SENS.: ATRIAL 0,6 mV - SENS.: VENTRICULAR

$1,6 \mathrm{mV}$ - FREQ: $62 \mathrm{ppm}$ - CONTR. ISOMETRICA DE $10 \mathrm{KGF}$ - DERIVAÇAO: TESTA - PERNA ESQUERDA

Fig. 14 - Paciente portador de um gerador de dupla-cámara com tele-anodo esternal espiral, programado para posição mais sensivel em átrio e ventriculo, sendo submetido a contração isométrica de $10 \mathrm{Kgf}$. Não existem interferências de miopotenciais esqueléticos. Derivação teste-perna esquerda. 
Com a estimulação cardíaca através de tele-anodo, consegue-se eliminar um outro tipo de complicação, que vem a ser a estimulação muscular da loja do marcapasso, mesmo quando se programa o gerador para sua voltagem máxima. Os autores utilizaram o tele-anodo intravascular apenas em ocasiōes especiais, como ocorreu em uma paciente que apresentava taquicardias ventriculares freqüentes, rebeldes à terapêutica clínica. Foi indicada ressecção da regiāo da reentrada em ventrículo, mas a paciente continuou a apresentar taquicardias refratárias. Foi indicado um implante de marcapasso com função antitaquicardia (Phylax Biotronik), o qual funcionava adequadamente. Entretanto, na clínica de marcapasso, com contração isométrica os miopotenciais esqueléticos, sentidos pelo gerador, que era unipolar, deflagravam o trem de pulsos antitaquicardia, desnecessariamente, provocando a taquicardia. Os autores transformaram o gerador em bipolar e colocaram um tele-anodo em cava inferior, visto que a paciente apresentava cirurgia anterior por via mediastínica. Sua evolução foi muito boa. Os geradores com função antitaquicardia necessitam ficar afastados dos miopotenciais esqueléticos e a estimulação cardíaca com tele-anodo é uma boa opção para esses casos.

Com relação ao tele-anodo intravascular, os autores têm observado que, por vezes, é dificil estabilizá-lo na região da veia cava inferior e, na região da cava superior, ou tronco venoso braquicefálico, provoca estimulação frênica ou peitoral. O tele-anodo intravascular em artéria pulmonar pode provocar arritmias, devido ao seu contato mecânico com o septo interventricular. A estimulação cardíaca com tele-anodo esternal espiral ou cilíndrico é a preferida. Atualmente, estão sendo desenvolvidos, por vários fabricantes, geradores com possibilidade de estimulaçāo unipolar e sensibilidade bipolar. Estes sistemas, na opinião dos autores, apresentam as seguintes desvantagens, em relação à técnica proposta:

1) existe necessidade de eletrodos bipolares em átrio e em ventrículo, nos casos de marcapasso de dupla-câmara; 2) continua existindo a possibilidade de estimulação muscular da loja; 3 ) o circuito eletrônico é mais complexo. Como desvantagem da estimulação cardiaca com tele-anodo, os autores fazem referência apenas à necessidade de mais um eletrodo e à necessidade de seu posicionamento.

\section{CONCLUSŌES}

A estimulação cardíaca com tele-anodo: 1) apresenta parâmetros per e pós-operatórios semeIhantes aos sistemas unipolares e bipolares convencionais; 2) diminui, significativamente, as inibições e reversōes assincrônicas por miopotenciais esqueléticos nos geradores unicâmara e dupla-câmara, mesmo programados para sua sensibilidade mais sensivel; 3) diminui, significativamente, a deflagração do circuito ventricular em freqüências altas, por miopotenciais esqueléticos, sentidos pelo circuito atrial dos geradores dupla-câmara, mesmo quando o gerador está programado para sua sensibilidade mais sensivel; 4) diminui, significativamente, nos marcapassos com função antitaquicardia, a deflagração indevida do gerador por miopotenciais esqueléticos; 5) evita as estimulações musculares de loja, mesmo quando o gerador está programado para voltagem alta; 6) evita as arritmias dos sistemas bipolares; 7$)$ permite melhor qualidade de vida ao paciente, liberando-o para a atividade física, quando isto é clinicamente possível. 
KORMANN, D. S.; PACHÓN MATEOS, J. C.; ALBORNOZ, R. N.; MEDEIROS. P. T. J.; CAMPOS, R.; KORMANN, S. J.; GIZZI, J. C.; SOUZA L. C. B.; PAULISTA, P. P.; SOUSA, J. E. M. R.; JATENE. A. D. - Cardiac stimulation with tele-anode: a new technique for electrical pacing of the heart Rev. Bras. Cir. Cardiovasc., 1(1): 1-13, 1986.

ABSTRACT: Unipolar pulse generators, either single or dual chamber, can be inhibited or reverted to the asynchronous mode, by skeletal muscle myopotentials. Dual chamber pacemakers may even stimulate the ventricle at the upper rate limit because of myopotential sensing via the atrial channel. A unipolar anti-tachycardia generator may be triggered by myopotentials to provoke an arrhythmia. During bipolar implanted pacing, episodic ventricular tachycardia has been induced in three patients with Chagasic cardiomyopathy and anodal stimulation has been shown to be the cause. Both unipolar and bipolar stimulation modes present problems. A stimulation mode with the cathode intracardiac and the anode remote from the generator and the patient's heart, called "tele-anode" was developed to be implanted in the presternal area or in venous system and avoid pacemaker triggering and inhibition. The subcutaneous "tele-anode" may be a spiral or a cylinder while an intravascular "tele-anode" may be positioned in the superior or inferior vena cava. Until March, 1986, 62 patients underwent "tele-anode" implantation, 57 at the sternum (51 spiral and 6 cylindrical) and 5 intramuscular. Thirty five generators were single chamber ventricular inhibited, 23 were dual chamber, 3 were atrial inhibited and 1 ventricular anti-tachycardia. In all cases the stimulation thresholds and electrogram characteristics were similar between intracardiac cathode and "tele-anode" and cathode and the puise generator site. Only electromyographic signals were consistently attenuated. One patient with an intravascular "tele-anode" died postoperatively of ventricular arrhythmias and one required ventricular lead repositioning. The 61 living patients, followed from one to twenty-one months, have shown no inhibition, triggering or noise mode reversion at nominal sensitivity setting. The authors conclude that pacemakers implanted with "tele-anode" show a clear evidence of decrease of associated complications, inherent to the conventional unipolar and bipolar cardiac stimulation system.

DESCRIPTORS: tele-anode; cardiac stimulation, techniques; pacemakers, cardiac.

\section{REFERÊNCIAS BIBLIOGRÁFICAS}

1 ANDERSON, S. T.; PITT, A.; WITHFORD, J. A.; DAVIS, B. B. - Interference with function of unipolar pacemaker due to muscle potentials. J. Thorac. Cardiovasc, Surg., 71: 698-703, 1976.

2 BRAGA, A. M. F. W.; KORMANN, D. S.; GAUCH, P. R. A.; KORMANN, S. J.; MENDES, M. L.; JATENE, A. D. - Reversão para freqüência assincrônica de marcapassos unipolares por miopotenciais. Arq. Bras. Cardiol., 37 (Supl. 1): 146, 1981. (Resumo)

3 BREIVIK, K. \& OHM, O. J. - Myopotential inhibition of unipolar QRS - inhibited (VVI) pacemakers, assessed by ambulatory Holter monitoring of the electrocardiogram. PACE, 3: 470, 1980.

4 FURMAN, S.; HURZELER, P.; MEHRA, R. - Cardiac pacing and pacemakers. IV. Threshold of cardiac stimulation. Am. Heart J., 94: 115-124, 1977.

5 FURMAN, S. \& MEHRA, R. - Anodal influence on ventricular fibrillation. Am. J. Cardiol., 33:137, 1984. (Resumo)

6 GABRY, M. D.; BEHRENS, M.; ANDREWS, C.; WANLISS, M.; KLEMENTOWICZ, P. T.; FURMAN, S. - Myopotential interference in programmable polarity DDD pacemakers. PACE, 9: A-279, 1986.

7 GAUCH, P. R. A.; KORMANN, D. S.; BURGOS, M. J.; MENDONÇA, E. F.; KORMANN, S. J.; JATENE, A. D.; - Inibiçōes de marcapassos unipolares frente a miopotenciais. Arq. Bras. Cardiol., 37 (Supl. 1): 148, 1981. (Resumo)
8 HAUSER, R. G. - Bipolar leads for cardiac pacing in the 1980s: a reappraisal provoked by skeletal muscle interference. PACE, 5: 34-37, 1982.

9 IRNICH, W. - Muscle noise behavior in pacemakers. PACE, 8: A-100, 1985.

10 KLEINERT, M. P.; GOYM, O.; FRANKE, E. - Bipolar electrode leads: are they the solution? PACE, 8:A-782, 1985.

11 KORMAN, D. S. - Material e método para avaliaçāo da ação de miopotenciais sobre marcapassos cardiacos implantáveis. Arq. Bras. Cardiol., 37 (Supl. 1): 148. 1981. (Resumo)

12 KORMANN, D. S.; GAUCH, P. R. A.; MENDONÇA, E.; KORMANN, S. J.; JATENE, A. D. - Transformação de marcapassos de demanda R-inibidos (VVI) unipolares em bipolares, no pré-operatório, mantendo-se o mesmo gerador, em casos de sua inibição por miopotenciais. Arq. Bras. Cardiol., 37: 341-345, 1981.

13 LEDESMA, C.; ARRIBAS, A.; LUENGO, C. M.; SALA, A.; PABON, P.; AVILA, C. - Incidence of myopotentials on implanted demand pacemakers. PACE, 8: A-2, 1985.

14 MELO, C. S.; KORMANN, D. S.; GAUCH, P. R. A.; KORMANN, S. J.; JATENE, M.; JATENE, A. D. - Resposta de marcapassos implantáveis frente a interfẹrências musculares. Arq. Bras. Cardiol., 34 (Supl. 1): 154, 1980. (Resumo)

15 MERX, W.; HAN, J.; YOON, M. S. - Effects of unipolar cathodal and bipolar stimulation on vulnerability of ischemic ventricles to fibrillation. Am. J. Cardiol., 35 : 37-41, 1975. 
MOND, H. G. - The cardiac pacemaker: function and malfunction. New York, Grune and Stratton, 1985. p. 416

MORACCHINI, P. V.; MELANDRI, F ; ALFANO, G.; TESORIERI, M. C.; TOSONI, G. D.; RIVA, U. R.; BOSCHI, S. - Bipolar versus unipolar pacing on myopotential interferences: report on 122 DDD unites. PACE, 8 A-96, 1985

MYMIN, D.; CUDDY, T. E.; SINHA, S. N.; WINTER, D A. - Inhibition of demand pacemakers by skeletal muscle potentials. JAMA, 223: 527-529, 1973

OHM, O. J.; BRULAND, H.; PEDERSEN, O. M.; WAER NESS, E. - Interference effect of myopotentials on function of unipolar demand pacemakers. Br. Heart J., 36: $77-84,1974$.

PARKER, B.; FURMAN, S.: ESCHER, D. J. W. - Input signals to pacemakers in a hospital environment. Ann. NY Acad. Sci, 167:823-834, 1969

P.ILLER, L. W, \& KENNELLY, B. M. - Myopotential inhibition of demand pacemakers. Chest, 66: 418-420. 1974.

22 PRESTON, T. A. - Anodal stimulation as a cause of pacemaker-induced fibrillation. Am. Heart J., 86: 336-372. 1973

23 RASSI, L.; KORMANN, D. S.; GAUCH, P. R. A.; KORMANN, S. J.: PEREIRA, C. A.; JATENE, A. D. - Eletrocardiografia dinâmica em pacientes portadores de marcapassos unipolares que apresentaram inibiçōes por miopotenciais na clínica de marcapasso. Arq Bras. Cardiol., 37 (Supl. 1): 81, 1981. (Resumo)

24 SECEMSKY, S. I.: HAUSER, R, G.: DENES, P : EDWARDS, L. M. - Unipolar sensing abnormalities: incidence and clinical significance of skeletal muscle interference and undersensing in 228 patients. PACE. 5 : $10-19,1982$

25 WIRTZFELD, A.; LAMPADIUS, M.: RUPRECHT, E. O. Unterdrückung von Demand-Schrittmachern durch Muskelpotentiale. Dtsch. Med. Wochenschr. 97: $61-66,1972$

\section{Discussão}

DR. PAULO BROFMAN Curitiba, $P R$

Sr. Presidente: quando recebi a comunicação de ter sido um dos escolhidos para comentar o trabalho, do Dr. Décio Kormann, confesso que fiquei bastante preocupado. Foi o Dr. Décio que, no início dos anos oitenta, começou a divulgar, em nosso meio, que a utilização de sistemas de estimulação com eletrodos unipolares apresentavam problemas sérios de inibição por miopotenciais e que esta complicação limitava o uso daquele sistema de estimulação. Naquela ocasiāo, nós discordamos, pois, em nossa experiência, a inibição por miopotenciais, comprovada na avaliação de rotina dos pacientes, resumia-se a 2 pacientes. Porém, com a evolução dos eletrodos bipolares, tornando-se mais finos, com superfícies de contato menores e com aletas na extremidade, facilitando, com isto, a fixação e estabilidade nas cavidades cardíacas, passamos a utilizar sistemas de estimulação com eletrodos bipolares e isto ocorreu na maioria dos Serviços no Brasil. Agora, passados 6 anos, o Dr. Décio alerta que os sistemas de estimulação por eletrodos bipolares também causam sérias complicaçōes, desencadeando taquiarritmias ou fibrilação ventricular, podendo, inclusive, levar à morte e recomenda um novo sistema, com mais um eletrodo. De imediato, novamente discordamos do autor, porque, em nossa experiência, não tínhamos nenhum caso detectado de taquiarritmias, ou de fibrilação ventricular que, comprovadamente, pudesse ter sido causada pela estimulação com eletrodos bipolares. Resolvemos, então, fazer um levantamento, na bibliografia mundial, para que pudéssemos contrapor a essa nova técnica, uma vez que julgávamos que a causa das complicaçōes apresentadas devia-se ao fato da simples presença do eletrodo como foco irritativo, para o desencadeamento daquelas arritmias em pacientes suscetiveis. Para nossa surpresa, esse tipo de complicação já vinha sendo alertado por diversos autores (Preston, Mehra, Greemberg, Ricci, Plubbs, Ken, etc.) e sempre relacionando essas arritmias com a estimulação com eletrodos bipolares, inclusive um deles afirma que, para minimizar os riscos de taquiarritmias induzidas por marcapassos, o eletrodo utilizado deva ser o unipolar.

Coincidentemente, quando faziamos este levantamento bibliográfico, um dos nossos pacientes começou a queixar-se de desmaios freqüentes. Ele é portador de um sistema de estimulação com eletrodo bipolar posicionado em cavidade ventricular direita. Anteriormente, este paciente tinha um sistema de estimulação unipolar endocavitário e foi necessária substituição, por apresentar inibiçōes por miopotenciais que levavam a importantes sintomas neurológicos. A avaliação ambulatorial do sistema de estimulação bipolar, por diversas vezes, apresentava funcionamento normal de marcapassos; apenas chamava a atenção a presença de algumas extrassístoles ventriculares no eletrocardiograma. $\mathrm{Na}$ avaliação com eletrocardiografia dinâmica ( $\mathrm{Hol}-$ ter), foi detectada uma grave arritmia tipo bigeminismo, porém sem relação com condução retrógrada e que causava comprometimento do débito cardiaco do paciente. Este tipo de arritmia não foi detectado, quando o paciente utilizava o sistema de estimulação com eletrodo unipolar, em diversos eletrocardiogramas dinâmicos (Holter). Isto leva a pensar que esse paciente possa estar apresentando as complicações descritas pelo autor, porém ainda estamos em fase de investigação. De qualquer forma, o sistema desenvolvido pelo Dr. Décio 
é interessante e merece ser acompanhado atentamente; porisso, cumprimentamos o autor, não só por este trabalho, mas por tudo de bom que tem produzido e divulgado na área de estimulação cardíaca artificial em nosso país.

DR. DOMINGO M. BRAILE

São José do Rio Preto

O Dr. Décio Kormann demonstrou, mais uma vez, sua criatividade e sua alta preocupação com os pacientes que trata. Tenho insistido, desde há muito, que o marcapasso é uma prótese e, como tal, deve ser encarada compromissando o médico e o paciente durante a evolução. Não basta implantar o marcapasso e pensar que todos os problemas do paciente estarão resolvidos. Freqüentemente, necessitamos ajustes, reprogramaçōes e mesmo trocas de sistemas, para atingir uma situação ideal, quando conseguimos atingí-la. O Dr. Décio demonstrou, de maneira sobeja, esta preocupação, seguindo seus pacientes de forma rotineira, acurada e inteligente, de tal forma a tirar conclusões e apresentar soluções para os diferentes problemas surgidos. Muitos dos pacientes em que empregamos a estimulação cardiaca artificial não têm só bloqueio A-V total; freqüentemente, são portadores de sérias arritmias, principalmente os chagásicos e o marcapasso pode representar um foco a mais arritmogênico com conseqüências funestas. O emprego dos sistemas bipolares e, agora, o uso do tele-anodo foram fruto da experiência e da determinação do Dr. Décio. Gostaria, contudo, de dizer que, no nosso material, fiz um estudo rápido, para saber qual a incidência da inibição por miopotenciais na prática clínica diária, que levava a sintomatologia incapacitante e verifiquei que ela era de $1,2 \%$ nos pacientes com eletrodo unipolar, que somam, no total, 950. Portanto, embora seja possivel provocar inibição do sistema por miopotenciais "em laboratório", isto não significa que, nó dia-a-dia, o paciente seja sintomático sempre. Quanto às arritmias mediadas pelo eletrodo bipolar, sem dúvida elas existem e o tratamento proposto pelo autor é de valia inestimável. Lembramos, contudo, que devem existir condiçōes favoráveis para a instalação e manutenção da arritmia para que o fenômeno se manifeste clinicamente. Devemos usar de toda a nossa dedicação para com os pacientes que estão submetidos à estimulação cardíaca e, como o Dr. Décio, ir a fundo no diagnóstico dos problemas, não nos conformando, de maneira simplista, de que tudo está bem, ou de que tudo está mal, porque o paciente é de mau prognóstico, com miocardiopatia avançada e irrecuperável. Muitas vezes, uma solução simples e inteligente, como a apresentada pelo autor, pode representar a diferença entre uma qualidade de vida melhor, ou pior, a vida ou a morte. Parabéns.

DR. KORMANN

(Encerrando)

Inicialmente, Sr. Presidente, queremos agradecer as elogiosas palavras do Dr. Brofman e do Dr. Braile. Como o Dr. Brofman, nós também ficamos assustados com os trabalhos existentes na literatura, a respeito do risco potencial e gênese de arritmias com sistemas bipolares. Acreditamos que o caso relatado pelo Dr. Brofman, realmente, possa ter sua arritmia provocada por estimulação anódica, a qual, às vezes, produz periodos curtos de arritmia, que atuam como "gatilho" para a deflagração de taquicardia ventricular originada em outra área de ventrículo esquerdo, ou direito. Nos casos suspeitos, há necessidade de cirurgia, com determinação dos períodos refratários efetivos de ventrículo com estimulação anódica e catódica. Caso exista uma diferença superior a $40 \mathrm{mseg}$ entre os dois, as arritmias poderão ser eliminadas através da estimulação com tele-anodo, sem substituição do gerador. Chamamos a atenção dos colegas para o fato de que deve existir um grande número de casos semelhantes, em nosso meio, principalmente entre pacientes chagásicos. Concordamos com - Dr. Braile, em relação aos cuidados que se deve tomar, com os pacientes portadores de marcapasso, prótese esta freqüentemente responsável pela manutenção de suas vidas. De acordo com nossa experiência e de acordo com os trabalhos dos autores que citamos, as inibiçōes, reversōes e đeflagraçōes por miopotenciais esqueléticos, em geradores unipolares, unicâmaras e dupla-câmaras, são, realmente, um problema muito grave, principalmente, quando é necessário deixar-se o gerador muito sensivel, devido a um retorno atrial,' ou ventricular muito baixo, independentemente do fabricante do marcapasso. Estes achados são apenas "de laboratório", mas podem ser comprovados através de eletrocardiografia dinâmica, correlacionando-se sintomas e achados eletrocardiográficos. Concordamos, também, com o Dr. Braile, em que, para que haja arritmia desencadeada pelos sistemas bipolares, devem existir condições predisponentes, às quais podem não estar presentes no momento do implante. Devido a estes fatos, preconizamos a estimulação cardíaca com tele-anodo como técnica de escolha para o tratamento dos distúrbios do sistema éxcito-condutor do coração. Muito obrigado. 